\title{
International variation in prevalence of rhinitis and its relationship with sensitisation to perennial and seasonal allergens
}

\author{
G. Weinmayr, F. Forastiere, S.K. Weiland ${ }^{\dagger}$, P. Rzehak, T. Abramidze, \\ I. Annesi-Maesano, B. Björkstén, B. Brunekreef, G. Büchele, W.O.C. Cookson, E. von \\ Mutius, R. Pistelli, D.P. Strachan and the ISAAC Phase Two Study Group
}

ABSTRACT: The relative importance of atopy in the aetiology of rhinitis is largely unknown. The present study investigated the geographical variations in rhinitis in relation to atopy.

The cross-sectional study involved 54,178 children (aged 8-12 yrs) from 30 study centres in 22 countries worldwide. Symptoms of rhinoconjunctivitis and rhinitis without conjunctivitis in the last 12 months were reported in parental questionnaires and children were skin-prick tested.

The prevalence of rhinoconjunctivitis and rhinitis without conjunctivitis varied widely (1.5-24.5\% and $1.4-45.2 \%$, respectively). For rhinoconjunctivitis, the population attributable fraction (PAF) varied $0-71 \%$ for a positive skin-prick test to one or more seasonal allergens and $0-41 \%$ for perennial allergens. The PAF for sensitisation to seasonal and perennial allergens was higher in affluent countries (36 and $25 \%$, respectively) than nonaffluent countries (1.3 and $12.6 \%$, respectively). For rhinitis without conjunctivitis, the PAF for perennial allergens was 8 and $4 \%$ for affluent and nonaffluent countries, respectively. No significant PAF was found for seasonal allergens.

Overall, atopy explained only a limited proportion of rhinitis symptoms, suggesting that the importance of other environmental factors has been under emphasised, particularly in less affluent countries. Atopy seems to be only marginally relevant for rhinitis without conjunctivitis, which seems mainly to reflect nonatopic rhinitis.

KEYWORDS: International Study of Asthma and Allergies in Childhood Phase Two study, perennial, population attributable risk, rhinitis, seasonal, skin-prick test

$\mathbf{R}$ hinitis is an important health problem affecting the quality of life of a large part of the child population. In Phase One of the International Study of Asthma and Allergies in Childhood (ISAAC) [1] the prevalence of rhinitis symptoms in the past 12 months ranged 3.2-66.6\% among 13-14-yr-old children. Furthermore, symptoms of allergic rhinitis seem to be increasing in some [2-5] but not all countries [6-9]. As for childhood asthma, the international differences in prevalence and the time trends for rhinitis are still not well understood. Recently, it has been shown that the importance of atopy as an aetiological factor for asthma varies considerably worldwide and is related to gross national income (GNI) [10].

Until recently research has focused on allergic rhinitis and the role of atopy. However, as early as 1988, JONES [11] reported on the importance of nonallergic perennial rhinitis and a more recent review of the published literature [12], which examined 22 population-based studies, indicated that indeed only half of all rhinitis cases (53\%) were attributable to atopy. The question remains as to how frequently rhinitis is attributable to atopy and how often symptoms that have been classically regarded as typical of allergic rhinitis are really attributable to atopy.

Traditionally, allergic rhinitis has been subdivided into seasonal and perennial types based on time and duration of symptom occurrence. For these two forms, perennial and seasonal allergens (house dust mites, animal dander and pollens) have been held responsible. In epidemiological studies in European populations, the presence of a runny/
AFFILIATIONS

For affiliation details see the Acknowledgements section. The members of the ISAAC Phase Two Study Group are also listed in the Acknowledgements.

\section{CORRESPONDENCE}

G. Weinmayr

Institute of Epidemiology

UIm University

Helmholtzstr. 22

D-89075 UIm

Germany

Fax: 4973150031069

E-mail: gudrun.weinmayr@

uni-ulm.de

Received:

November 232007

Accepted after revision:

June 092008

SUPPORT STATEMENT

G. Weinmayr is the recipient of a

European Respiratory Society

Fellowship. For full details of the

local funding agencies see the

Acknowledgements section.

\section{STATEMENT OF INTEREST}

A statement of interest for the study itself can be found at

www.erj.ersjournals.com/misc/

statements.shtml 
blocked nose with conjunctivitis in the absence of a cold proved to identify those individuals with allergic rhinitis [1, 13, 14].

The present authors investigated geographical variations in rhinitis in childhood. The following two groups were defined: 1) rhinoconjunctivitis, likely to contain most of the individuals with allergic rhinitis; and 2) rhinitis without conjunctivitis, expected to include both nonallergic and allergic rhinitis. The importance of sensitisation to seasonal and perennial allergens was explored, and the worldwide variation in the population attributable fractions (PAF) was assessed for the two categories of rhinitis. The present study is based on Phase Two of ISAAC [15]. It is the first investigation to compare standardised data from several different centres worldwide which have applied the same protocol for assessing rhinitis symptoms and particularly, for determining atopic sensitisation. An interesting feature of ISAAC Phase Two is the possibility to carry out both ecological and individual comparisons.

\section{MATERIALS AND METHODS}

The methods used in the ISAAC Phase Two study are described in detail elsewhere [15] and in the online supplementary data. Briefly, 30 study centres from 22 countries (table 1) drew random samples of $\sim 1,000$ children from the classes in which the majority were aged 9-11 yrs. All studies and coordination were approved by local ethics committees [15]. The parents were invited to fill in a standardised, selfadministered questionnaire. The questions were identical to those used in the ISAAC Phase One study for 6-7-yr-old children $[1,15,16]$. The question "In the past 12 months, has your child had a problem with sneezing or a runny or blocked nose, when he/she did not have a cold or the flu?"' (Yes/No) was followed by (if Yes) "In the past 12 months, has this nose problem been accompanied by itchy-watery eyes?" In countries in which illiteracy is a problem (Ecuador, India, Brazil and Ghana) the questions were posed by trained interviewers. In most centres, all children were invited to undergo a skin-prick test. Several centres drew a random sub-sample (table 1 and online supplementary data) [15].

Skin-prick tests were performed with six common aeroallergens and, in addition, centres were encouraged to test allergens of local relevance. Seasonal allergens comprised mixed tree pollen and mixed grass pollen, perennial allergens were Dermatophagoides pteronyssinus, D. farinae and cat hair. Alternaria and local allergens were classified as either perennial or seasonal depending on the location (information obtained from the centre principle investigator; see online supplementary data). The skin-prick test for sensitisation to seasonal or perennial allergens was considered to be positive if at least one seasonal or perennial allergen yielded a positive test result. A positive skin-reaction was defined as a wheal diameter of $\geqslant 3 \mathrm{~mm}$, after subtraction of the negative control.

\section{Statistical analysis}

Children aged 8-12 yrs were included in the analysis. Spearman correlation coefficients were calculated for the correlation between prevalence rates of symptoms and positive skin-prick test reactivity. According to ISAAC policy, reported frequencies from study centres with $<60 \%$ participation for parental questionnaires should not be interpreted as prevalence estimates and were, therefore, not included in the ecological comparisons.

At the individual level, the association between specific symptoms and a positive skin-prick test was assessed with prevalence rate ratios (PRR) within centres [17]. Since children sensitised to perennial allergens are more likely to be sensitised to seasonal allergens, and vice versa, adjusted PRRs were calculated with the other group of allergens considered as the adjustment variable. Initial models also included sex, number of siblings and parental allergy, but none of these variables notably influenced the obtained estimate and were therefore omitted from the final model.

The PAFs (\%) were calculated using the following formula [18]:

$$
\mathrm{PAF}=\mathrm{Pec} \times(\mathrm{PRR}-1) / \mathrm{PRR}
$$

where $\mathrm{Pec}$ is the prevalence of exposure among the cases (i.e. children with rhinitis). Combined estimates of the PRR and PAF across several study centres were calculated using random effects meta-analysis models [19].

As asthma prevalence and the role of atopy may vary between affluent countries with a "Western" lifestyle and less affluent countries, the countries were grouped on the basis of GNI per capita, converted into US dollars using the World Bank Atlas method [20]. The first group (affluent countries) consisted of high-income countries (GNI >US\$9,200 in 2001) [21] and included most European centres, essentially EU members before 2004, New Zealand and Hong Kong (China). The other group (nonaffluent countries) comprised all other centres.

\section{RESULTS}

Questionnaire data on rhinitis symptoms for 54,178 children aged 8-12 yrs and skin-prick data on allergen-specific sensitisation for 31,759 children were included in the analysis. Participation rates varied $35-100 \%$ (median $83 \%$ ) for the questionnaire, and 24-99.9\% (median 67\%) for the skin-prick test (table 1).

\section{Prevalence of symptoms}

The prevalence of rhinoconjunctivitis symptoms ranged from $1.5 \%$ in Pichincha province (Ecuador) to $24.5 \%$ in Almeria (Spain), and the prevalence of rhinitis without conjunctivitis ranged from $2.7 \%$ in Pichincha province to $29.1 \%$ in Guangzhou (China; table 1).

The prevalence of sensitisation to any of the perennial airborne allergens tested also varied widely between centres, from $1.4 \%$ in Ghana to $45.2 \%$ in Hong Kong (table 2). The prevalence of skin-prick test sensitisation to any of the seasonal allergens varied from $0.1 \%$ in Ghana to $25.8 \%$ in Tromsø (Norway).

\section{Ecological correlations}

There was a significant correlation between rhinoconjunctivitis and sensitisation to seasonal $(\rho=0.5, p=0.019)$ but not perennial allergens $(\rho=0.2, p=0.38$; fig. 1$)$. However, for rhinitis without conjunctivitis, there was a significant correlation with sensitisation to perennial $(\rho=0.54, p=0.007)$ but not with seasonal allergens $(\rho=-0.05, \mathrm{p}=0.84)$. 
TABLE 1 Participation and prevalence of symptoms by centre

Country and centre Participation rhinitis questionnaire

Children $\mathrm{n} \quad$ Participation rate

Prevalence of symptoms in the past year

Rhinitis with Rhinitis without conjunctivitis conjunctivitis
Participation skin-prick test

Children $\mathbf{n} \quad$ Participation rate

\section{Albania}

Tirana\#

Brazil

Uruguaiana\#

China

Beijing ${ }^{\#}$

Guangzhou\#

Hong Kong

Ecuador

Pichincha province ${ }^{\#}$

Estonia

Tallinn"

France

Créteil

Georgia

Tbilisi $^{\#}$

Germany

Dresden

Munich

Ghana

Kintampo \#

Greece

Athens

Thessaloniki

Iceland

Reykjavik

India

Bombay ${ }^{\#}$

Italy

Rome

Latvia

Riga $^{\#}$

Netherlands

Utrecht

New Zealand

Hawkes Bay

Norway

Tromsø
Palestine

Ramallah"

Spain

Almeria

Cartagena

Madrid

Valencia

Sweden

Linköping

Östersund

\section{Turkey}

Ankara\#

UK

West Sussex

1045

1971

4207

3502

3010

894

966

1373

951

3013

3271

1354

985

1018

935

1656

1346

906

3527

1320

3675

2293

1127

1402

964

1349

904

1193

2966

1055
94.3

96.3

92.3

93.1

96.7

100.0

83.4

64.8

82.7

82.5

86.7

ND

85.3

63.0

46.5

ND

82.9

87.3

64.4

84.3

81.5

84.8

49.9

53.7

35.2

40.1

81.4

85.9

87.3

78.5
6.7

21.0

7.5

7.0

12.4

1.5

5.6

14.6

7.0

12.1

12.8

ND

4.8

7.1

11.2

4.9

9.6

8.6

9.7

22.3

12.6

6.9

24.5

15.4

18.7

12.6

13.8

12.2

11.8

16.2
14.6

9.9

23.2

29.1

15.2

2.7

11.4

15.4

9.6

9.9

8.3

ND

12.9

12.7

6.3

5.3

11.5

15.7

15.3

12.8

7.4

10.1

13.4

9.5

13.4

10.4

5.1

8.9

17.7

7.4
929

1192

84.0

96.2

90.8

36.1

63.8

99.9

55.5

75.9

61.6

60.6

ND

85.3

63.0

38.0

ND

62.3

30.8

43.3

82.2

60.2

65.0

47.7

39.6

23.9

30.5

77.0

71.4

81.0

66.7

Data are presented as \%, unless otherwise stated. ND: no data available. ${ }^{\#}:$ centres in countries with a gross national income per capita $<$ US $\$ 9,200$ in 2001 (nonaffluent countries); ${ }^{\circ}$ the core standard allergens were not licensed in France, where allergens from Stallergènes (Antony, France) were tested in 1,451 children. 
TABLE 2 Prevalence of positive skin-prick tests (SPT) to perennial and seasonal allergens

\begin{tabular}{|c|c|c|c|c|}
\hline \multirow{2}{*}{ Country and centre } & \multicolumn{2}{|c|}{ Positive SPT to perennial allergens } & \multicolumn{2}{|c|}{ Positive SPT to seasonal allergens } \\
\hline & Prevalence \% & Positives $\mathbf{n}$ & Prevalence \% & Positives $\mathrm{n}$ \\
\hline Tirana & 12.4 & 115 & $6.4^{\#}$ & 59 \\
\hline \multicolumn{5}{|l|}{ Brazil } \\
\hline \multicolumn{5}{|l|}{ China } \\
\hline Beijing & $22.9^{\#}$ & 239 & 3.0 & 31 \\
\hline Guangzhou & $31.5^{\#}$ & 340 & 1.9 & 21 \\
\hline Hong Kong & $45.2^{\#}$ & 599 & 1.2 & 16 \\
\hline \multicolumn{5}{|l|}{ Ecuador } \\
\hline Ecuador & $18.1^{\#}$ & 162 & 2.5 & 22 \\
\hline \multicolumn{5}{|l|}{ Estonia } \\
\hline \multicolumn{5}{|l|}{ Germany } \\
\hline Dresden & 16.2 & 365 & 18.4 & 415 \\
\hline Munich & 13.2 & 306 & 16.1 & 372 \\
\hline \multicolumn{5}{|l|}{ Ghana } \\
\hline Kintampo & 1.6 & 21 & 0.1 & 1 \\
\hline \multicolumn{5}{|l|}{ Greece } \\
\hline Athens & 9.2 & 91 & $8.2^{\#}$ & 81 \\
\hline Thessaloniki & 21.2 & 216 & $12.8^{\#}$ & 130 \\
\hline \multicolumn{5}{|l|}{ India } \\
\hline Bombay & 5.8 & 90 & 2.1 & 32 \\
\hline \multicolumn{5}{|l|}{ Iceland } \\
\hline \multicolumn{5}{|l|}{ Italy } \\
\hline \multicolumn{5}{|l|}{ New Zealand } \\
\hline Hawkes Bay & 27.6 & 355 & 22.6 & 291 \\
\hline \multicolumn{5}{|l|}{ Norway } \\
\hline Tromsø & 20.1 & 145 & 25.8 & 186 \\
\hline \multicolumn{5}{|l|}{ Palestine } \\
\hline Ramallah & $10.3^{\#}$ & 25 & $0.5^{\#}$ & 1 \\
\hline \multicolumn{5}{|l|}{ Spain } \\
\hline Almeria & 41.5 & 446 & 7.0 & 75 \\
\hline Cartagena & 22.0 & 227 & $3.9^{\#}$ & 40 \\
\hline Madrid & 19.4 & 127 & $25.6^{\#}$ & 167 \\
\hline Valencia & 12.5 & 128 & $3.0^{\#}$ & 31 \\
\hline Sweden & & & & \\
\hline Linköping & $11.8^{\#}$ & 101 & 16.7 & 143 \\
\hline Öestersund & $18.6^{\#}$ & 184 & 19.2 & 190 \\
\hline Turkey & & & & \\
\hline Ankara & $15.8^{\#}$ & 433 & $15.2^{\#}$ & 418 \\
\hline UK & & & & \\
\hline West Sussex & 10.6 & 95 & 11.1 & 100 \\
\hline
\end{tabular}

\#: local allergens were tested in addition to a standard set of six common allergens. 

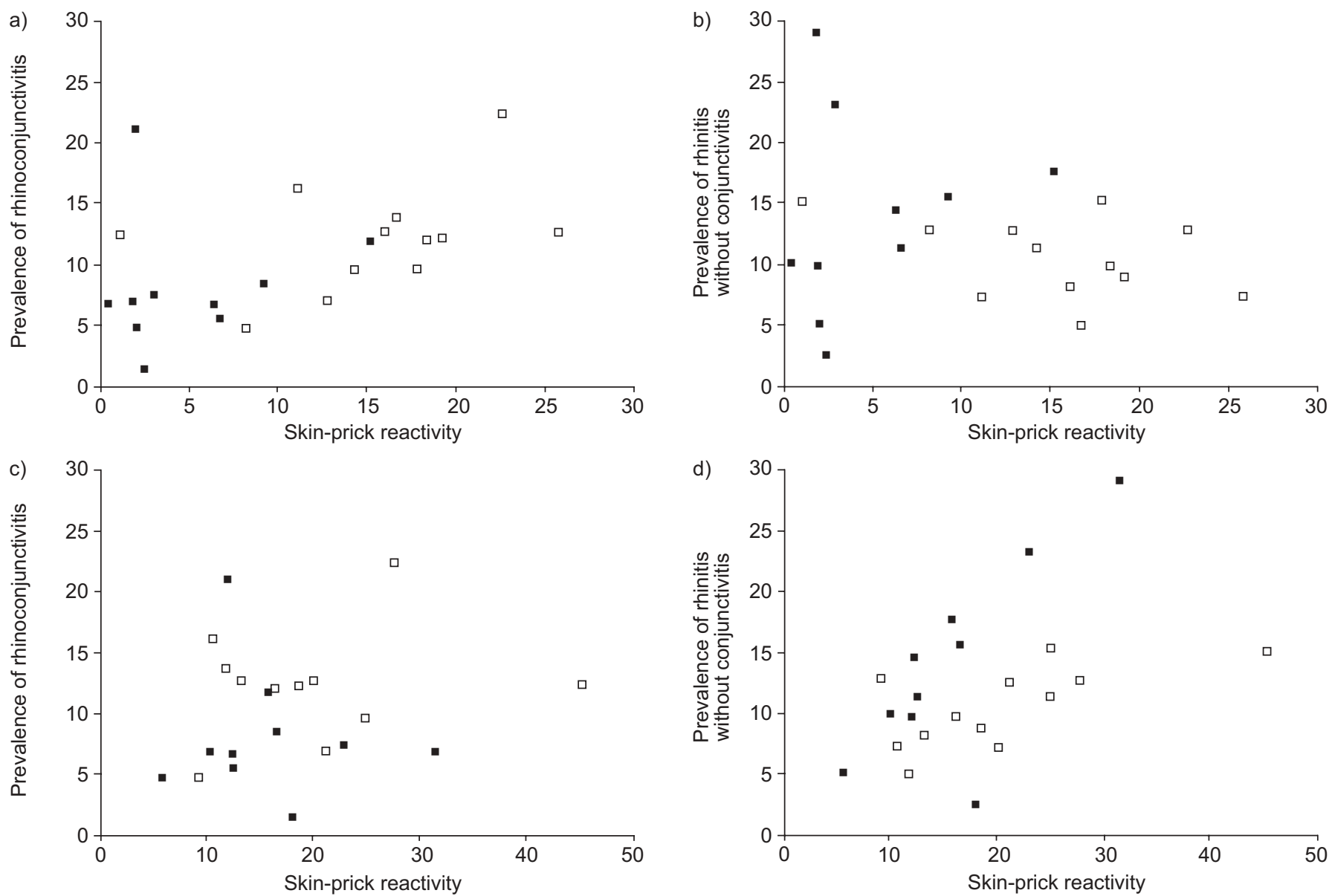

FIGURE 1. Scatter plots of the prevalence of rhinitis symptoms versus the prevalence of a positive skin-prick test to a and b) seasonal allergens, and $c$ and d) perennial allergens. $\square$ : affluent countries; $\mathbf{\square}$; nonaffluent countries. a) Spearman correlation coefficient $0.50, p=0.02$; b) Spearman correlation coefficient $0.05, p=0.84 ; c)$ Spearman correlation coefficient $0.20, p=0.38$; d) Spearman correlation coefficient $0.54, p=0.01$.

\section{Associations based on individuals and PAFs}

The association between rhinitis and sensitisation to perennial/seasonal allergens is presented in figure 2 (crude PRR) and table 3 (PRR adjusted for seasonal/perennial allergens).

\section{Rhinoconjunctivitis}

The adjusted association between rhinoconjunctivitis and perennial allergens was positive in all but three centres (Ankara, Turkey; Beijing, China; and Ramallah, Palestine). The remaining adjusted PRR ranged from 1.1 in Tirana (Albania) to 4.1 in Cartagena (Spain). For affluent centres, the combined estimate was 2.2 (95\% confidence interval 1.8-2.6) and for nonaffluent centres it was 1.5 (1.1-2.1).

Adjusted PAFs varied from $0.9 \%$ in Tirana (Albania) to $57.4 \%$ in Hong Kong (table 4). For affluent centres the combined PAF was $25.0 \%(18.1-31.4 \%)$, whereas among nonaffluent centres, only $12.6 \%(2.7-21.6 \%)$ were attributable to perennial allergens.

Sensitisation to seasonal allergens was positively associated with rhinoconjunctivits in all centres except Tirana (Albania) and Bombay (India), and the remaining adjusted PRR ranged from 1.0 in Ankara (Turkey) and Almeria (Spain) to 9.0 in Tromsø (Norway). The combined estimate was 3.6 (2.6-5.0) for affluent centres and 1.6 (1.1-2.4) for nonaffluent centres.
PAF ranged from $\sim 0 \%$ in Almeria (Spain), Bombay (India) and Tirana (Albania) to $71.3 \%$ in Tromsø (Norway). The PAF were highest in the Scandinavian centres and Dresden (Germany). The combined estimate was $35.9 \%(23.6-46.2 \%)$ and $1.3 \%$ $(0-2.8 \%)$ for affluent and nonaffluent centres, respectively. When considering outdoor and indoor allergens together in all centres, the overall PAF was 56\%.

Rhinitis without conjunctivitis

For the association between sensitisation to perennial allergens, the adjusted PRR ranged from 0.3 in Linköping (Sweden; not statistically significant) to 2.2 in Rome (Italy). The combined estimate for affluent centres was 1.5 (1.3-1.7) and 1.2 (1.1-1.4) for nonaffluent centres.

PAFs ranged from $0 \%$ in Bombay (India) and Linköping (Sweden) to $24.9 \%$ in Hong Kong. Combined estimates gave a PAF of $8.0 \%(5.5-10.5 \%)$ for affluent countries and $4.0 \%(1.2-6.6 \%)$ for nonaffluent countries.

There was no association between sensitisation to seasonal allergens and rhinitis without conjunctivitis. The PRR estimates were not statistically significant in any centre. The estimates for the combined PRR were $1.0(0.9-1.1)$ for affluent and $1.1(0.9-1.3)$ for nonaffluent centres. 
a)

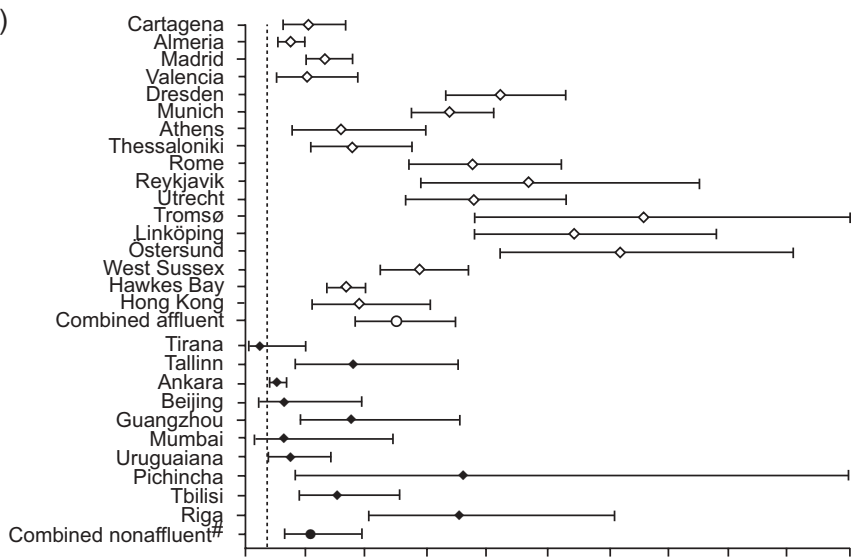

c)

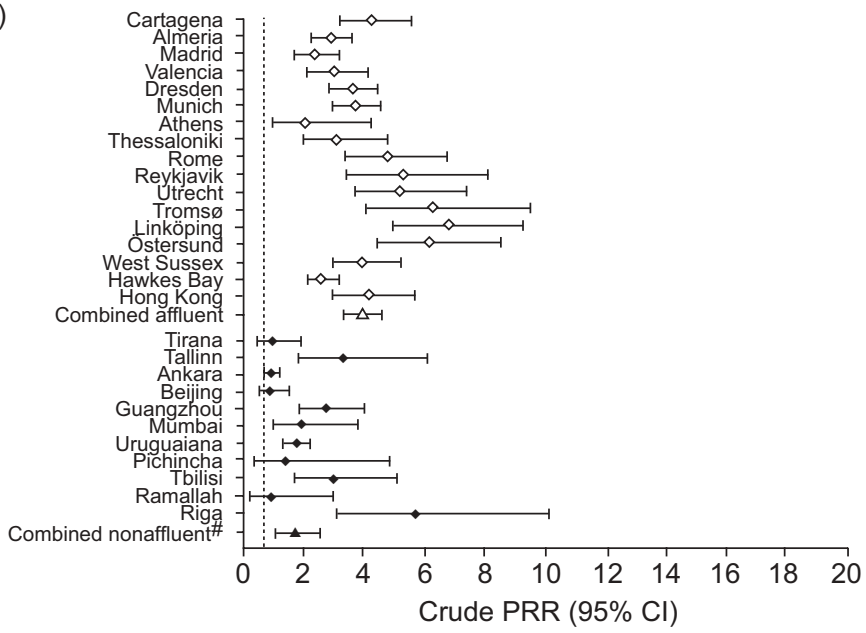

b)

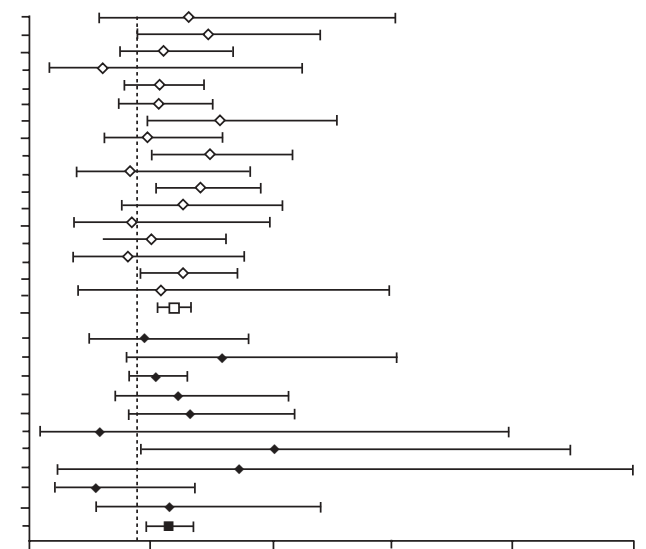

d)

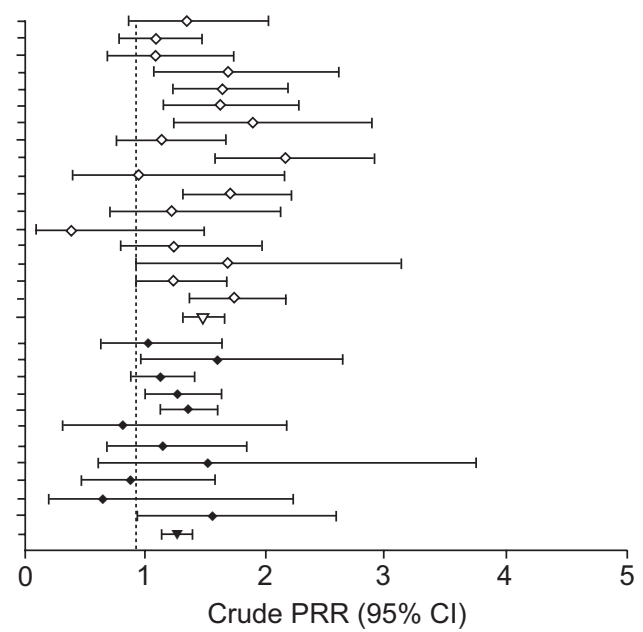

FIGURE 2. Association between rhinitis symptoms and a positive skin-prick test to seasonal and perennial allergens. a) Rhinoconjunctivitis versus seasonal allergens, b) rhinitis without conjunctivitis versus seasonal allergens, c) rhinoconjunctivitis versus perennial allergen and d) rhinitis without conjunctivitis versus perennial allergens. a) $\bigcirc$ 4.99 (3.60-6.91); : 2.16 (1.22-3.82); b) $\square: 1.18$ (1.06-1.32); $\mathbf{\square}: 1.14$ (0.96-1.35); c) $\triangle: 3.87$ (3.30-4.54); $\mathbf{\Delta}: 1.69$ (1.11-2.56); d) $\nabla: 1.47$ (1.31-1.65); $\mathbf{\nabla}: 1.25$ (1.13-1.39). PRR: prevalence rate ratios. ${ }^{*}$ : does not include Tbilisi, Georgia (see online supplementary data).

Combined estimates of PAF were $2.1 \%$ (95\% CI $-0.3-4.5 \%)$ for affluent countries and $0.6 \%$ (95\% CI $-0.5-1.6 \%)$ for nonaffluent countries. The overall PAF of the sensitisation to seasonal and perennial allergen for rhinitis, with and without conjunctivitis, was $33 \%$.

\section{DISCUSSION}

The present study indicates great variation in rhinitis symptom prevalence and its relationship to atopic sensitisation. Generally, both the ecological and the individual-based analyses showed a strong association of rhinoconjunctivitis with sensitisation to perennial and seasonal allergens, whereas for rhinitis without conjunctivitis a relationship could only be seen with perennial allergens. The PAFs due to atopy varied greatly and were considerably higher among affluent than nonaffluent centres.

There are strengths and limitations of the current study that are worth discussing. The present authors obtained information on rhinitis and atopic sensitisation for children in 29 centres worldwide, more than any previous study. All centres were comparable methodologically. In particular, the skin-prick test was performed according to the same protocol using the same extracts and the same staff-training procedures [15]. In addition, allergens of local relevance were also included. However, with respect to the standard test set of six allergens, effect measures (odds ratios and PAF) were only slightly changed by inclusion of local allergens. The countries analysed were selected based on the findings from the ISAAC Phase One study to ensure that the global variety of the disease prevalence was captured. Therefore, the current results are likely to represent the worldwide variation in the relationship between sensitisation to allergens and rhinitis. However, one clear limitation of the present study is that, in some centres, response rates were low and it cannot be fully excluded that sick children are over-represented. This may have increased the prevalence estimate for rhinitis symptoms and the considered risk factors. However, the influence on the association between rhinitis and skin-prick tests will probably only be minor as long as the selection factors have operated in the same manner for rhinitis and atopy. Indeed, the estimated odds ratio and PAFs changed very little when these additional allergens were omitted from the analyses. Finally, it cannot be ruled out that there was a certain degree of misclassification 
TABLE 3 Association of rhinitis with conjunctivitis and rhinitis without conjunctivitis with positive skin-prick tests to perennial and seasonal allergens

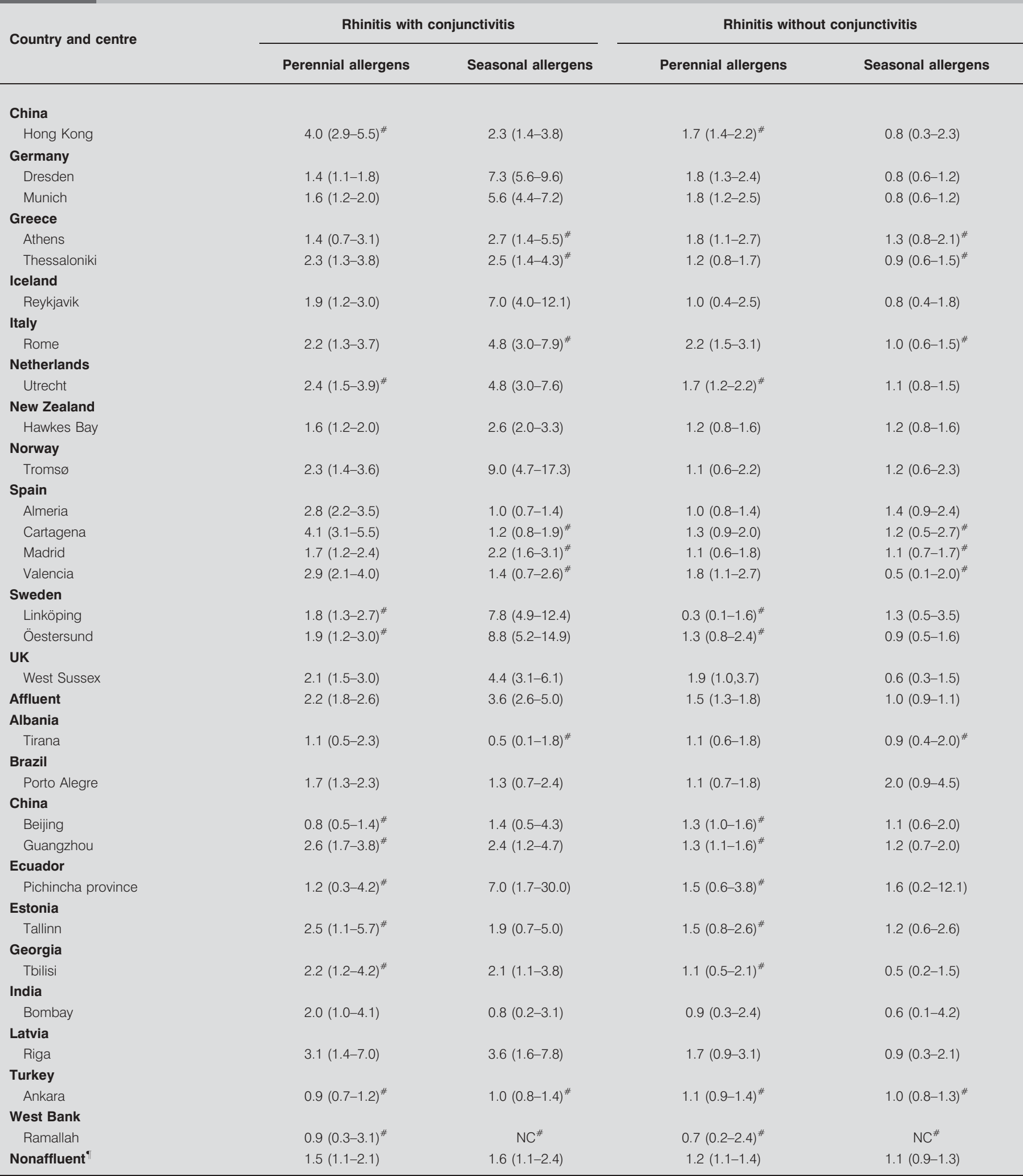

Data are presented as adjusted prevalence rate ratios (95\% confidence interval). The prevalence rate ratio for perennial allergens is adjusted for seasonal allergens and vice versa. NC: not calculated due to no observations. ${ }^{\#}$ : local allergens were tested in addition to a standard set of six common allergens; $\bullet$ : analysis does not include Tbilisi, Georgia (see online supplementary data). 
TABLE 4 Population attributable fraction (PAF) of symptoms of rhinitis with and without conjunctivitis caused by sensitisation to perennial allergens and seasonal allergens

\begin{tabular}{|c|c|c|c|c|}
\hline \multirow{2}{*}{ Country and centre } & \multicolumn{2}{|c|}{ PAF of symptoms of rhinitis with conjunctivitis } & \multicolumn{2}{|c|}{ PAF of symptoms of rhinitis without conjunctivitis } \\
\hline & Perennial allergens & Seasonal allergens & Perennial allergens & Seasonal allergens \\
\hline Hong Kong & $57.4(45.1-66.9)^{\#}$ & $2.4(0.3-4.6)$ & $24.9(13.6-34.7)^{\#}$ & $0.0^{\circ}$ \\
\hline \multicolumn{5}{|l|}{ Germany } \\
\hline \multicolumn{5}{|l|}{ Greece } \\
\hline Athens & $5.1(-7.8-16.5)$ & $13.4(0.2-24.9)^{\#}$ & $6.8(0.1-13.0)$ & $2.6(-3.5-8.2)^{\#}$ \\
\hline Thessaloniki & $24.6(7.5-38.5)$ & $20.0(6.4-31.5)^{\#}$ & $3.1(-6.3-11.8)$ & $0.0^{\# \cdot 9}$ \\
\hline \multicolumn{5}{|l|}{ Iceland } \\
\hline Reykjavik & $21.0(4.5-34.6)$ & $56.6(39.7-68.7)$ & $0.6(-12.3-12.0)$ & $0.0^{\circ}$ \\
\hline \multicolumn{5}{|l|}{ New Zealand } \\
\hline Hawkes Bay & $16.2(7.4-24.1)$ & $29.2(21.8-35.9)$ & $4.5(-6.7-14.5)$ & $3.4(-6.4-12.4)$ \\
\hline \multicolumn{5}{|l|}{ Norway } \\
\hline Tromsø & $33.4(15.1-47.7)$ & $71.3(54.7-81.9)$ & $2.5(-12.7-15.7)$ & $4.9(-12.7-20.0)$ \\
\hline \multicolumn{5}{|l|}{ Spain } \\
\hline Almeria & $42.7(33.2-50.8)$ & $0.1(-3.2-3.3)$ & $1.6(-12.8-14.2)$ & $3.0(-2.0-7.8)$ \\
\hline Cartagena & $40.5(30.9-48.8)$ & $1.3(-2.4-4.8)^{\#}$ & $6.6(-4.8-16.7)$ & $0.8(-3.6-4.9)^{\#}$ \\
\hline Madrid & $14.4(4.3-23.3)$ & $25.2(13.5-35.3)^{\#}$ & $1.2(-9.3-10.7)$ & $1.9(-10.7-13.1)^{\#}$ \\
\hline Valencia & $18.7(10.8-25.9)$ & $1.6(-1.9-5.1)^{\#}$ & $8.1(0.2-15.4)$ & $0.0^{\# \cdot 9}$ \\
\hline \multicolumn{5}{|l|}{ Sweden } \\
\hline Linköping & $20.8(9.0-31.1)^{\#}$ & $56.7(44.0-66.6)$ & $0.0^{\# \cdot 9}$ & $3.4(-10.2-15.2)$ \\
\hline Porto Alegre & $8.0(2.9-12.7)$ & $0.6(-1.3-2.5)$ & $1.0(-5.7-7.2)$ & $2.0(-1.2-5.0)$ \\
\hline \multicolumn{5}{|l|}{ China } \\
\hline Beijing & $0.0^{\#, 9}$ & $1.1(-3.2-5.2)$ & $5.7(-0.7-11.7)^{\#}$ & $0.3(-1.8-2.3)$ \\
\hline Guangzhou & $33.6(17.5-46.5)^{\#}$ & $3.8(-0.7-8.0)$ & $9.6(3.3-15.4)^{\#}$ & $0.4(-0.9-1.7)$ \\
\hline \multicolumn{5}{|l|}{ Ecuador } \\
\hline Pichincha province & $3.3(-30.0-28.0)^{\#}$ & $13.2(-8.5-30.5)$ & $8.1(-15.4-26.8)^{\#}$ & $1.6(-6.8-9.3)$ \\
\hline \multicolumn{5}{|l|}{ Estonia } \\
\hline Tallinn & $19.1(-0.2-34.6)^{\#}$ & $9.5(-5.3-22.2)$ & $6.0(-4.5-15.5)^{\#}$ & $1.9(-5.7-8.9)$ \\
\hline \multicolumn{5}{|l|}{ India } \\
\hline Bombay & $5.1(-2.2-11.8)$ & $0.0^{\circ}$ & $0.0^{\circ}$ & $0.0^{\circ}$ \\
\hline \multicolumn{5}{|l|}{ Latvia } \\
\hline Riga & $32.1(6.9-50.4)$ & $28.6(10.3-43.1)$ & $9.4(-3.1-20.4)$ & $0.0^{\circ}$ \\
\hline \multicolumn{5}{|l|}{ Turkey } \\
\hline Ankara & $0.0^{\#, 9}$ & $0.6(-4.0-5.1)^{\#}$ & $1.9(-2.0-5.7)^{\#}$ & $0.0^{\# \cdot 9}$ \\
\hline Nonaffluent $^{+}$ & $12.6(2.7-21.6)$ & $1.3(-0.2-2.8)$ & $4.0(1.2-6.6)$ & $0.6(-0.5-1.6)$ \\
\hline
\end{tabular}

Data are presented as adjusted PAF in \% (95\% confidence interval). The PAF for perennial allergens is adjusted for seasonal allergens and vice versa. ${ }^{\#}$ : local allergens were tested in addition to a standard set of six common allergens; " : not computed as the prevalence rate ratio was $<1$ and the PAF would, therefore, have a noninterpretable value (PAF $<0){ }^{+}$: analysis does not include Ramallah (Palestine) and Tbilisi (Georgia; see online supplementary data). 
due to differential reporting of symptoms, which may be related to cultural differences [1].

A strong variation in rhinitis symptom prevalence has been previously found in ISAAC Phase One [1]. Published estimates of PAFs of atopy for rhinitis are limited and mostly based on studies conducted in industrialised affluent countries. ZACHARASIEWICZ et al. [12] analysed the contribution of atopy to rhinitis, reviewing questionnaire data and skin-prick test results from 20 studies including 57 centres. However, only five nonaffluent countries were included and only eight centres studied children aged $<14$ yrs. The estimated average PAF for any reported rhinitis symptoms or hay fever diagnosis was $\sim 53 \%$. For the subgroup "symptoms related to allergen exposure" (or "seasonal symptoms"), the PAF was $48 \%$. In addition, there seems to be some indication that the PAF are lower for children than adults $[12,13]$. The present result for rhinoconjunctivitis in affluent countries is similar (56\%) but when considering rhinitis without any further distinction the PAF is only $33 \%$. However, any comparison with the study by ZACHARASIEWICZ et al. [12] has to be considered with caution, due to the variety of definitions used for rhinitis in different studies and the fact that the subjects in most studies were outside the age range investigated in the ISAAC Phase Two study.

The combination of the two ISAAC questions on rhinitis (rhinitis symptoms accompanied by itchy-watery eyes) is a useful epidemiological instrument to measure mainly the occurrence of allergic rhinitis, at least in European populations $[13,14]$. For example, the positive predictive value for detecting atopy, i.e. the proportion of children with a positive skin-prick test among those who reported rhinoconjunctivitis, was $64 \%$ in a Swiss population [13]. The current results show that atopy is an important risk factor for rhinoconjunctivitis but is only marginally relevant for rhinitis without conjunctivitis, which mainly seems to reflect nonatopic rhinitis. Seasonal and perennial allergens accounted for 36 and $25 \%$ of the prevalence of rhinoconjunctivitis in affluent countries, respectively, and 12.6 and $1.3 \%$ in nonaffluent countries, respectively. The PAF of rhinitis without conjunctivitis was much lower for seasonal and perennial allergens in both affluent (8 and 2.1\%, respectively) and nonaffluent countries (4 and $0.6 \%$, respectively). This suggests that the role of sensitisation is less important than has been previously assumed, even among children with symptoms generally considered to be characteristic of allergic rhinitis.

This conclusion is true even when considering a methodological limitation of the present study, namely that skin-prick tests alone were used to define atopy. Positive skin-prick tests are not a perfect measure of an allergy of the nasal mucosa, and nasal provocation with allergen extracts may be more specific when investigating allergic rhinitis. However, this does not necessarily imply that the PAFs based on skin-prick tests underestimate the real value. Indeed, while the PRR may increase when using a more specific exposure measure, the prevalence of the measured exposure may decrease. For example, when examining PAFs for asthma due to atopy with a stricter definition (reaction to at least two or three allergens as opposed to at least one allergen) the PAF for asthma proved to be lower [18].
The predominant role of seasonal allergens, in particular pollen, for rhinoconjunctivitis (measuring the classic "hay fever") among affluent centres is in line with conventional wisdom and several epidemiological studies [13, 22, 23]. In contrast, the PAFs for seasonal allergens were generally lower or equal to PAFs for perennial allergens among nonaffluent centres. This may indicate that pollen does not play the major role in many of these countries. Results from a previous study in China [24] also follow in this direction; rhinitis was more strongly associated with sensitisation to house dust mites than to the variety of pollen tested.

Results pointing towards a dissociation of sensitisation and supposedly allergic disease in nonaffluent areas have previously been found for asthma. For example, in Ethiopia, no association was found between asthma and sensitisation to house dust mites in a nonaffluent rural area, in contrast to an urban more affluent area [25]. The reasons for such dissociation are not clear and have not been specifically addressed. The role of infection with parasites or other microbial agents and their influence on allergies has been discussed previously [25]. Evidence in support of such a role stems from other investigations $[26,27]$.

One factor the present authors did not consider was food allergy. However, sensitisation to food allergens decreases with age between infancy and childhood, whereas sensitisation to aero-allergens increases [28-30]. Thus, it seems unlikely that taking into account sensitisation to food allergens would substantially alter the current results. Hypersensitivity to food additives, such as preservatives and colouring agents, may also induce symptoms of rhinitis [31]. However, these agents may partly be trigger factors rather than aetiological factors [32].

Traditionally, it has been recognised that there are allergic and nonallergic forms of noninfectious rhinitis. In children, certain forms of nonallergic rhinitis linked to occupational exposures or certain medications are presumably of little importance, other mechanisms implying an autonomic dysfunction leading to vasomotor rhinitis may play a role.

In many centres, the proportion of rhinitis without conjunctivitis, i.e. mainly nonallergic forms of rhinitis, relative to rhinoconjunctivitis is considerable or even higher. This and the relatively low fraction of rhinitis that could be attributed to atopy in the present study strongly suggest that risk factors not related to allergy are also of great importance, especially in nonaffluent countries.

However, to date, studies on the influence of nonallergic risk factors on rhinitis and, especially, rhinoconjunctivitis are relatively scarce. Risk factors that have been associated with noninfectious rhinitis include parental smoking, smoking during pregnancy/breastfeeding, high birth weight, early introduction of foods or formula, respiratory infections, central heating with gas and space heating, synthetic bedding, dampness or mould at home, and air pollution [24, 33-35]. Some of these factors have been investigated within the Phase Two ISAAC study and their influence will be the subject of future analyses.

In conclusion, the present results highlight a high international variation in prevalence of rhinitis-related symptoms and atopic 
sensitisation, and also in the underlying association between sensitisation and rhinitis. The strength of this association varies strongly between countries and is lower overall than has been previously suspected. In particular, mechanisms unrelated to atopy seem to play a major role in nonaffluent countries. This emphasises the need to investigate environmental risk factors for rhinitis.

\section{ACKNOWLEDGEMENTS}

The affiliation details for the authors of the study are as follows. G. Weinmayr, S.K. Weiland, P. Rzehak, G. Büchele: Institute of Epidemiology, Ulm University, Ulm; P. Rzehak: Helmholtz Zentrum München German Research Center for Environmental Health, Institute of Epidemiology, Neuherberg and Institute of Medical Data Management, Biometrics and Epidemiology, Ludwig-Maximilians-University, Munich; E. von Mutius: Dr. von Haunersches University Children's Hospital, Ludwig-Maximilians-University, Munich (all Germany). F. Forastiere: Dept of Epidemiology, Local Health Authority Rome; R. Pistelli: Dept of Respiratory Physiology, Catholic University (both Rome, Italy). T. Abramidze: Center of Allergy and Immunology, Tbilisi (Georgia). I. AnnesiMaesano: EPAR, U707 INSERM, Medical School St-Antoine, Paris (France). B. Björkstén: Institute of Environmental Medicine, Karolinska Institutet Stockholm (Sweden). B. Brunekreef: Institute for Risk Assessment Sciences, University of Utrecht, and Julius Center for Health Sciences and Primary Care, University Medical Center Utrecht (both Utrecht, The Netherlands). W.O.C. Cookson: Wellcome Trust Centre for Human Genetics, University of Oxford, Oxford; D.P. Strachan: St. Georges's, University of London, London (both UK).

The coordination and central laboratory analyses of the European centres were funded by the Fifth Framework Programme of European Commission (QLK4-CT-1999-01288).

The following bodies funded the local studies. Spain: Fondo de Investigacion Sanitaria (grant code 00/1092E; Almeria); Fondo de Investigacion Sanitaria (grant code 00/1092E ; Cartagena); Fondo de Investigacion Sanitaria (grant code 00/1092E; Madrid); Fondo de Investigacion Sanitaria (grant code 00/ 1092E; Valencia). Turkey: Scientific and Technical Research Council of Turkey (grant code SPAG-2237), Treatment and Research Foundation of Turkey for Allergy, Asthma and Immunology and the Research foundation of Hacettepe University, Faculty of Medicine (Ankara). Greece: The Thorax Foundation Research Center (Athens); The Thorax Foundation Research Center (Thessaloniki). France: French Institute of Health and Medical Research (Institut National de la Santé et de la Recherche Médicale (INSERM), grant code IDS 337/4D001D and 737/69480), Ministère de l'Emploi et de la Solidarité (grant code 227/7HL02D), Mutuelle Générale de l'Education Nationale (grant code 257/8PL01F) and Agence de l'Environnement et de la Maitrise de l'Energie ADEME/ PRIMEQUAL 96 (grant code FJ012B; Créteil). Germany: German Ministry of Education and Research (grant code 01 EE 9411-3; Dresden); German Ministry of Education and Research (grant code 01 EE 9411-3; Munich); Rudolf and Clothilde Eberhardt-Foundation (Ulm). Italy: Lazio Regional Health Authority (Rome). New Zealand: Health Research
Council of New Zealand, Asthma and Respiratory Foundation of New Zealand and Hawkes Bay Medical Research Foundation (Hastings). Sweden: The Swedish Foundation for Health Care Sciences and Allergy Research (Linköping and Östersund). India: Jaslok Hospital \& Research Centre (Mumbai). West Bank: Al-Quds University, Directorate General for International Cooperation and Belgian Technical Cooperation (Ramallah). The Netherlands: Dutch Ministries of the Environment, of Health and of Transport (Utrecht). UK: South Thames National Health Service Regional and Development project SPGS (West Sussex). The centres in Mumbai, Ankara, Kintampo (Ghana), Riga (Latvia), Tallinn (Estonia), Tblisi (Georgia) and Tirana (Albania) were supported, at least in part, by European members of the ISAAC Steering Committee.

The members of the ISAAC Phase Two Steering Group are as follows. B. Björkstén (Stockholm, Sweden), B. Brunekreef (Utrecht, the Netherlands), W.O.C. Cookson (Oxford, UK), D.P. Strachan (London, UK), E. von Mutius (Munich, Germany), S.K. Weiland ${ }^{\dagger}$ (ISAAC Phase Two Coordinator; Ulm, Germany).

The ISAAC Phase Two Coordinating and Data Centre: S.K. Weiland $^{\dagger}$ (Director), G. Büchele, C. Dentler, A. Kleiner, P. Rzehak, G. Weinmayr (Institute of Epidemiology, Ulm University, Ulm, Germany).

The Principal Investigators and Scientific Team were as follows. A. Priftanji, A. Shkurti, J. Simenati, E. Grabocka, K. Shyti, S. Agolli, A. Gurakuqi (Tirana, Albania); R.T. Stein, M. Urrutia de Pereira, M.H. Jones, P.M. Pitrez (Uruguaiana, Brazil); P.J. Cooper, M. Chico (Pichincha province, Ecuador); Y.Z. Chen (Beijing, China); N.S Zhong (Guangzhou, China); C. Lei (National Coordinator), G. Wong (Hong Kong, China); M-A. Riikjärv, T. Annus (Tallinn, Estonia); I. Annesi-Maesano (Créteil, France); M. Gotua, M. Rukhadze, T. Abramidze, I. Kvachadze, L. Karsanidze, M. Kiladze, N. Dolidze (Tblisi, Georgia); W. Leupold, U. Keil, E von Mutius, S.K. Weiland ${ }^{\dagger}$ (Dresden, Germany); E. von Mutius, U. Keil, S.K. Weiland (Munich, Germany); P. Arthur ${ }^{\dagger}$, E. Addo-Yobo (Kintampo, Ghana); C. Gratziou (National Coordinator), C. Priftis, A. Papadopoulou, C. Katsardis (Athens, Greece); J. Tsanakas, E. Hatziagorou, F. Kirvassilis (Thessaloniki, Greece); M. Clausen (Reykjavik, Iceland); J.R. Shah, R.S. Mathur, R.P. Khubchandani, S. Mantri (Mumbai, India); F. Forastiere, R. Di Domenicantonio, M. De Sario, S. Sammarro, R. Pistelli, M.G. Serra, G. Corbo, C.A. Perucci (Rome, Italy); V. Svabe, D. Sebre, G. Casno, I. Novikova, L. Bagrade (Riga, Latvia); B. Brunekreef, D. Schram, G. Doekes, P.H.N. Jansen-van Vliet, N.A.H. Janssen, F.J.H. Aarts, G. de Meer (Utrecht, the Netherlands); J. Crane, K. Wickens, D. Barry (Hawkes Bay, New Zealand); W. Nystad, R. Bolle, E. Lund (Tromsø, Norway); J. Batlles Garrido, T. Rubi Ruiz, A. Bonillo Perales, Y. Gonzalez Jiménez, J. Aguirre Rodriguez, J. Momblan de Cabo, A. Losilla Maldonado, M. Daza Torres (Almeria, Spain); L. GarcíaMarcos (National Coordinator), A. Martinez Torres, J.J. Guillén Pérez, A. Piñana López, S. Castejon Robles (Cartagena, Spain); G. García Hernandez, A. Martinez Gimeno, A.L. Moro Rodríguez, C. Luna Paredes, I. Gonzalez Gil (Madrid, Spain); M.M. Morales Suarez-Varela, A. Llopis González, A. Escribano Montaner, M. Tallon Guerola 
(Valencia, Spain); L. Bråbäck (National Coordinator), M. Kjellman, L. Nilsson, X-M. Mai (Linköping, Sweden); L. Bråbäck, A. Sandin (Östersund, Sweden); Y. Saraçlar, S. Kuyucu, A. Tuncer, C. Saçkesen, V. Sumbuloğlu, P. Geyik, C. Kocabaş (Ankara, Turkey); D.P. Strachan, B. Kaur (West Sussex, UK); N. El-Sharif, B. Nemery, F. Barghuthy, S. Abu Huij, M. Qlebo (Ramallah, West Bank).

The ISAAC Steering Committee is as follows. N. Ait-Khaled (Paris, France); H.R. Anderson and D.P. Strachan (London, UK); W. Cookson (Oxford, UK); H. Williams (Nottingham, UK); I. Asher, P. Ellwood, A. Stewart and E. Mitchell (Auckland, New Zealand); J. Crane, N. Pearce and R. Beasley (Wellington, New Zealand); B. Björkstén (Stockholm, Sweden); B. Brunekreef (Utrecht, the Netherlands); S. Foliaki (Nuku'alofa, Kingdom of Tonga); L. García-Marcos (Murcia, Spain); U. Keil and E. von Mutius (Munich, Germany); S.K. Weiland $^{\dagger}$ (Ulm, Germany); C. Lai and G. Wong (Hong Kong, China); J. Mallol (Santiago, Chile); S. Montefort (Naxxar, Malta); J. Odhiambo (Nairobi, Kenya); and C. Robertson (Parkville, Australia).

This paper is dedicated to S.K. Weiland, University Professor and Director of the Institute of Epidemiology in Ulm, who died suddenly and unexpectedly in 2007, shortly after having given his comments on the advanced draft of this paper. As a founding member of the ISAAC and the coordinator of ISAAC Phase Two he played a leading role in international studies of asthma and allergy and a crucial role in the conception of all work leading up to the publication of this manuscript. He will be fondly remembered as a teacher and researcher of great warmth, enthusiasm and wisdom.

The authors would like to thank all the children, parents, teachers, field workers and lab workers for their enormous contributions to this collaborative study.

\section{REFERENCES}

1 Strachan D, Sibbald B, Weiland S, et al. Worldwide variations in prevalence of symptoms of allergic rhinoconjunctivitis in children: the International Study of Asthma and Allergies in Childhood (ISAAC). Pediatr Allergy Immunol 1997; 8: 161-176.

2 Lee SL, Wong W, Lau YL. Increasing prevalence of allergic rhinitis but not asthma among children in Hong Kong from 1995 to 2001 (Phase 3 International Study of Asthma and Allergies in Childhood). Pediatr Allergy Immunol 2004; 15: 72-78.

3 von Mutius E, Weiland SK, Fritzsch C, Duhme H, Keil U. Increasing prevalence of hay fever and atopy among children in Leipzig, East Germany. Lancet 1998; 351: 862-866.

4 Maziak W, Behrens T, Brasky TM, et al. Are asthma and allergies in children and adolescents increasing? Results from ISAAC phase I and phase III surveys in Munster, Germany. Allergy 2003; 58: 572-579.

5 Selnes A, Nystad W, Bolle R, Lund E. Diverging prevalence trends of atopic disorders in Norwegian children. Results from three cross-sectional studies. Allergy 2005; 60: 894-899.
6 Braun-Fahrländer C. No further increase in asthma, hay fever and atopic sensitisation in adolescents living in Switzerland. Eur Respir J 2004; 23: 407-413.

7 Anderson HR, Ruggles R, Strachan DP, et al. Trends in prevalence of symptoms of asthma, hay fever, and eczema in 12-14 year olds in the British Isles, 1995-2002: questionnaire survey. BMJ 2004; 328: 1052-1053.

8 Kalyoncu AF, Selcuk ZT, Enunlu T, et al. Prevalence of asthma and allergic diseases in primary school children in Ankara, Turkey: two cross-sectional studies, five years apart. Pediatr Allergy Immunol 1999; 10: 261-265.

9 Asher MI, Montefort S, Bjorksten B, et al. Worldwide time trends in the prevalence of symptoms of asthma, allergic rhinoconjunctivitis, and eczema in childhood: ISAAC Phases One and Three repeat multicountry cross-sectional surveys. Lancet 2006; 368: 733-743.

10 Weinmayr G, Weiland SK, Bjorksten B, et al. Atopic sensitization and the international variation of asthma symptom prevalence in children. Am J Respir Crit Care Med 2007; 176: 565-574.

11 Jones AS. Non-allergic perennial rhinitis. Biomed Pharmacother 1988; 42: 499-503.

12 Zacharasiewicz A, Douwes J, Pearce N. What proportion of rhinitis symptoms is attributable to atopy? J Clin Epidemiol 2003; 56: 385-390.

13 Braun-Fahrländer C, Wuthrich B, Gassner $\mathrm{M}$, et al. Validation of a rhinitis symptom questionnaire (ISAAC core questions) in a population of Swiss school children visiting the school health services. SCARPOL-team. Swiss Study on Childhood Allergy and Respiratory Symptom with respect to Air Pollution and Climate. International Study of Asthma and Allergies in Childhood. Pediatr Allergy Immunol 1997; 8: 75-82.

14 Charpin D, Sibbald B, Weeke E, Wüthrich B. Epidemiologic identification of allergic rhinitis. Allergy 1996; 51: 293-298.

15 Weiland SK, Björkstén B, Brunekreef B, Cookson WO, von Mutius E, Strachan DP. Phase II of the International Study of Asthma and Allergies in Childhood (ISAAC II): rationale and methods. Eur Respir J 2004; 24: 406-412.

16 Asher MI, Keil U, Anderson HR, et al. International Study of Asthma and Allergies in Childhood (ISAAC): rationale and methods. Eur Respir J 1995; 8: 483-491.

17 Greenland S. Model-based estimation of relative risks and other epidemiologic measures in studies of common outcomes and in case-control studies. Am J Epidemiol 2004; 160: 301-305.

18 Pearce N, Pekkanen J, Beasley R. How much asthma is really attributable to atopy? Thorax 1999; 54: 268-272.

19 Normand SL. Meta-analysis: formulating, evaluating, combining, and reporting. Stat Med 1999; 18: 321-359.

20 The World Bank Group. World Bank Atlas Method. http:/ / web.worldbank.org/WBSITE/EXTERNAL/DATASTATISTICS/ 0,,contentMDK:20452009 menuPK:2236139 pagePK:64133150 piPK:64133175 theSitePK:239419,00.html.

21 The World Bank Group. Glossary: High-income country. www.worldbank.org/depweb/english/modules/glossary. html\#high-income Date last updated: 2003. Date last accessed: September 22, 2007.

22 Schäfer T, Hoelscher B, Adam H, Ring J, Wichmann HE, Heinrich J. Hay fever and predictive value of prick test and 
specific IgE antibodies: a prospective study in children. Pediatr Allergy Immunol 2003; 14: 120-129.

23 Sears MR, Burrows B, Flannery EM, Herbison GP, Holdaway MD. Atopy in childhood. I. Gender and allergen related risks for development of hay fever and asthma. Clin Exp Allergy 1993; 23: 941-948.

24 Leung R, Ho P, Lam CW, Lai CK. Sensitization to inhaled allergens as a risk factor for asthma and allergic diseases in Chinese population. J Allergy Clin Immunol 1997; 99: 594-599.

25 Yemaneberhan H, Bekele Z, Venn A, Lewis S, Parry E, Britton J. Prevalence of wheeze and asthma and relation to atopy in urban and rural Ethiopia. Lancet 1997; 350: 85-90.

26 Palmer LJ, Celedón JC, Weiss ST, Wang B, Fang Z, Xu X. Ascaris lumbricoides infection is associated with increased risk of childhood asthma and atopy in rural China. Am J Respir Crit Care Med 2002; 165: 1489-1493.

27 Scrivener S, Yemaneberhan $\mathrm{H}$, Zebenigus $\mathrm{M}$, et al. Independent effects of intestinal parasite infection and domestic allergen exposure on risk of wheeze in Ethiopia: a nested case-control study. Lancet 2001; 358: 1493-1499.

28 Kulig M, Bergmann R, Klettke U, Wahn V, Tacke U, Wahn U. Natural course of sensitization to food and inhalant allergens during the first 6 years of life. J Allergy Clin Immunol 1999; 103: 1173-1179.
29 Arshad SH, Tariq SM, Matthews S, Hakim E. Sensitization to common allergens and its association with allergic disorders at age 4 years: a whole population birth cohort study. Pediatrics 2001; 108: E33.

30 Huang HW, Lue KH, Wong RH, Sun HL, Sheu JN, Lu KH. Distribution of allergens in children with different atopic disorders in central Taiwan. Acta Paediatr Taiwan 2006; 47: 127-134.

31 Fuglsang G, Madsen G, Halken S, Jørgensen S, Ostergaard PA, Osterballe $\mathrm{O}$. Adverse reactions to food additives in children with atopic symptoms. Allergy 1994; 49: 31-37.

32 Pacor ML, Di Lorenzo G, Martinelli N, Mansueto P, Rini GB, Corrocher R. Monosodium benzoate hypersensitivity in subjects with persistent rhinitis. Allergy 2004; 59: 192-197.

33 Lee YL, Shaw CK, Su HJ, et al. Climate, traffic-related air pollutants and allergic rhinitis prevalence in middle-school children in Taiwan. Eur Respir J 2003; 21: 964-970.

34 Wright AL, Holberg CJ, Martinez FD, Halonen M, Morgan W, Taussig LM. Epidemiology of physician-diagnosed allergic rhinitis in childhood. Paediatrics 1994; 94: 895-901.

35 Zacharasiewicz A, Zidek T, Haidinger G, et al. Symptoms suggestive of atopic rhinitis in children aged 6-9 years and the indoor environment. Allergy 2000; 55: 945-950. 